\title{
Effects of different backbone binders on the characteristics of zirconia parts using wax-based binder system via ceramic injection molding
}

\author{
Jiaxin $\mathrm{WEN}^{a}$, Zhipeng $\mathrm{XIE}^{b,{ }^{*}}$, Wenbin $\mathrm{CAO}^{a}$, Xianfeng $\mathrm{YANG}^{c}$ \\ ${ }^{a}$ School of Materials Science and Engineering, University of Science and Technology Beijing, Beijing 100084, China \\ ${ }^{b}$ State Key Laboratory of New Ceramics and Fine Processing, Department of Materials Science and Engineering, \\ Tsinghua University, Beijing 100084, China \\ ${ }^{c}$ College of Physics and Electronics Science, Changsha University of Science \& Technology, Changsha 410014, China
}

Received: June 19, 2016; Revised: August 22, 2016; Accepted: August 25, 2016

(C) The Author(s) 2016. This article is published with open access at Springerlink.com

\begin{abstract}
In this work, various backbone binders were used in wax-based binder system to formulate zirconia parts by ceramic injection molding (CIM). The effect of different backbone binders on the molding, debinding, and sintering behaviors was investigated. After blending process, the feedstock using multi-polymer components exhibited more homogeneous structure compared with that using the mono-polymer ones due to the synergistic effect of multi-polymers. During solvent debinding, some defects such as "slumping" and "peeling" appeared in the parts containing ethylene-vinyl acetate copolymer (EVA), but they were not found in the parts with other thermal polymers. Also, as for the parts after sintering, the one using low density polyethylene (LDPE) and high density polyethylene (HDPE) as backbone binders presented a more uniform microstructure with finer zirconia grains among all the investigated compositions, and thus obtained the highest flexural strength ( $\sim 949 \mathrm{MPa}$ ) and relative density $(\sim 98.9 \%)$.
\end{abstract}

Keywords: ceramic injection molding (CIM); $\mathrm{ZrO}_{2}$; backbone binders; solvent debinding; sintering

\section{Introduction}

Ceramic injection molding (CIM) has drawn great attention for decades, as it takes the capacity of massive production of ceramic parts with complex shape and high dimensional precision [1]. During CIM, the feedstock is essentially composed of ceramic powder and organic binder. As an important component of the powder-binder suspension, the organic binder not only endows the flowability of the suspension but also keeps the integrity of the green and debound parts. From the perspective of injection molding process, the binder should have good adhesion and low contact angle to the

\footnotetext{
* Corresponding author.

E-mail: xzp@mail.tsinghua.edu.cn
}

powder [2]. In the delivering process during CIM, the green and debound parts with applicable strength would be better. German [3] suggested that the suitable green strength should be greater than $5 \mathrm{MPa}$. So the binder is usually a complex mixture which is comprised of backbone binder (to support and maintain the integrity of parts before debinding), lubricant which usually is wax or low molecular weight polymer (with the aim to improve the rheological properties of mixture), and a small quantity of surfactant (to serve as a bridge between binder and ceramic powder) [4,5]. Hence, adopting a suitable binder system is the key factor to achieve the parts with excellent properties by CIM.

In the last decades, several backbone binders for wax-based binder system were developed, and the more familiar ones are based on thermoplastics, such as 
ethylene-vinyl acetate copolymer (EVA) [6], polypropylene (PP) [7], low density polyethylene (LDPE) [8], high density polyethylene (HDPE) [9], and HDPE and EVA blend [10], for powder injection molding. In addition, it has been widely acknowledged that wax-based binder system could only be eliminated by thermal debinding or solvent debinding. Among them, solvent debinding $[3,10]$ with the advantages of avoiding defects in the shape of parts and reducing total debinding time has predominated in the debinding process. However, the organic solvents such as n-heptane, trichloroethane, and methylene chloride usually adopted in solvent debinding are flammable, carcinogenic, and poorly recyclable [11]. It is worth mentioning that kerosene with low toxicity and low cost could be a good alternative [12]. For this approach, small molecular weight binders (paraffin wax and stearic acid) are firstly eliminated to form the interconnected pore paths which facilitate the decomposed air produced by the thermal pyrolysis of remaining binder expel from the parts during the next thermal debinding process.

In this paper, we have adopted the combination of solvent (kerosene) and thermal debinding techniques to eliminate the binders from injection molded parts. In contrast to previous researches about backbone binders mainly focusing on rheological behavior [13,14], pore structure evolution [15], and debinding process [16,17], investigations on the molding behavior and sintered properties have been made in this study with aim to explore the suitable backbone binders for achieving the defect-free and excellent mechanical properties of parts in wax-based binder system via CIM.

\section{Experimental}

The ceramic powder used was commercial zirconia ( $3 \mathrm{~mol} \% \mathrm{Y}_{2} \mathrm{O}_{3}$ ) with the particle size $D_{50}$ of $0.16 \mu \mathrm{m}$ and Brunauer-Emmett-Teller (BET) specific area of $8.2 \mathrm{~m}^{2} / \mathrm{g}$ (grade YSZ-F-DM-3.0, Fanmeiya Advanced Materials Co. Ltd., Jiujiang, China), which are offered by the supplier. Morphology of the powder is shown in Fig. 1.

The binder system contained $45 \mathrm{wt} \%$ backbone polymer, $46 \mathrm{wt} \%$ paraffin wax $(\mathrm{PW}$, density $=$ $0.90 \mathrm{~g} / \mathrm{cm}^{3}$ ) as the primary component, $4 \mathrm{wt} \%$ stearic acid $\left(\mathrm{SA}\right.$, density $\left.=0.88 \mathrm{~g} / \mathrm{cm}^{3}\right)$ as the surfactant, and $5 \mathrm{wt} \%$ dibutyl phthalate (DBP, density $=1.02 \mathrm{~g} / \mathrm{cm}^{3}$ ) as the plasticizer. We chose four different backbone

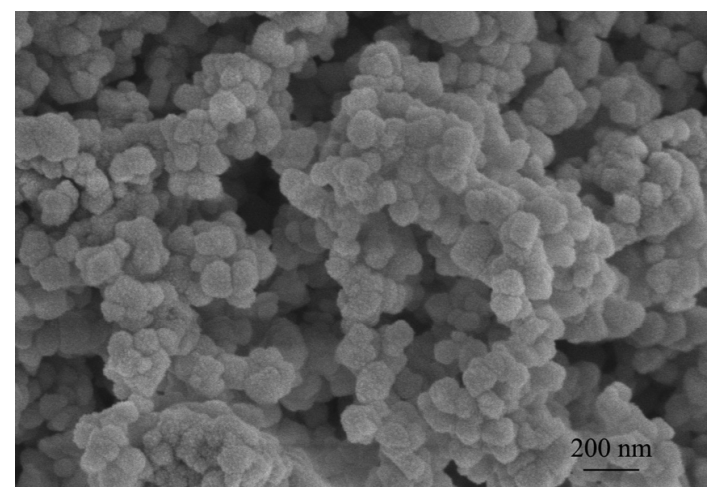

Fig. 1 Morphology of zirconia powder observed by scanning electron microscopy (SEM).

polymers: ethylene-vinyl acetate copolymer (EVA, density $=0.91-0.94 \mathrm{~g} / \mathrm{cm}^{3}$ ) in which VA content is $14 \%$, low density polyethylene (LDPE, density $=0.915$ $0.94 \mathrm{~g} / \mathrm{cm}^{3}$ ), high density polyethylene (HDPE, density $\left.=0.96 \mathrm{~g} / \mathrm{cm}^{3}\right)$, and polypropylene (PP, density = $0.91 \mathrm{~g} / \mathrm{cm}^{3}$ ), for feedstock formulation and designated them as feedstock 1, 2, 3, and 4 respectively. Also, multi-polymers (EVA and HDPE, LDPE and HDPE, as well as PP and HDPE) were chosen as the backbone binders for feedstock formulation and referred to as feedstock 5, 6, and 7, respectively. The solid loading was fixed as $88 \mathrm{wt} \%$ (54.6 vol\%), which was determined in our earlier work [12], and the composition of organic vehicles (binders) utilized in the experiments is summarized in Table 1.

Mixing experiments of binder and zirconia powder were conducted in a twin screw kneader (SK-160, ShangHai Rubber Machinery, China) with a mixing bowl of $2 \mathrm{~L}$ and operated at a rate of $11 \mathrm{rpm}$. For the kneading process, the backbone binder was first heated to $140-170{ }^{\circ} \mathrm{C}$ in a kneader. Second, zirconia powder was added to form a mixture with the backbone binder

Table 1 Composition of the organic binders used

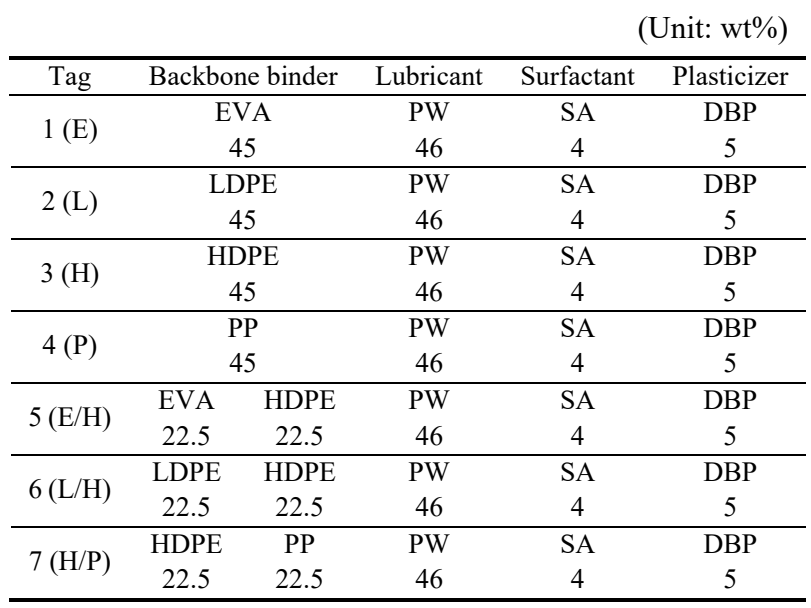


for $10-15 \mathrm{~min}$. Subsequently, the lubricant PW and the surfactant SA were gradually added in the kneader. Finally, the plasticizer DBP was slowly added into the mixture. Each feedstock mixing process lasted about $40 \mathrm{~min}$ and the homogeneity of feedstock was determined using Accupyc II Gas Pycnometer [18].

The organic component was eliminated through a combination of solvent and thermal debinding. The solvent debinding was performed by immersion of samples in kerosene at $60{ }^{\circ} \mathrm{C}$. The thermal cycle was designed on the basis of thermo-gravimetrical analysis (TGA) of the binder and feedstock. TGA was conducted on the DSC/TG analyzer (STA 409 PC/PG, Netzsch, Germany) with a heating rate of $5{ }^{\circ} \mathrm{C} / \mathrm{min}$ up to $600{ }^{\circ} \mathrm{C}$ in air atmosphere. TGA of binder components and feedstocks with various backbone binders is shown in Fig. 2. After debinding, all the parts were sintered at a heating rate of $2.5{ }^{\circ} \mathrm{C} / \mathrm{min}$ to $1500{ }^{\circ} \mathrm{C}$ for $2 \mathrm{~h}$ in air atmosphere. The microstructure of sintered body was observed by means of field emission scanning electron microscopy (FESEM, LEO1530, Germany) operated at $15 \mathrm{kV}$. Before microstructural observations, the sintered bodies were thermally etched at $1400{ }^{\circ} \mathrm{C}$ for $30 \mathrm{~min}$.
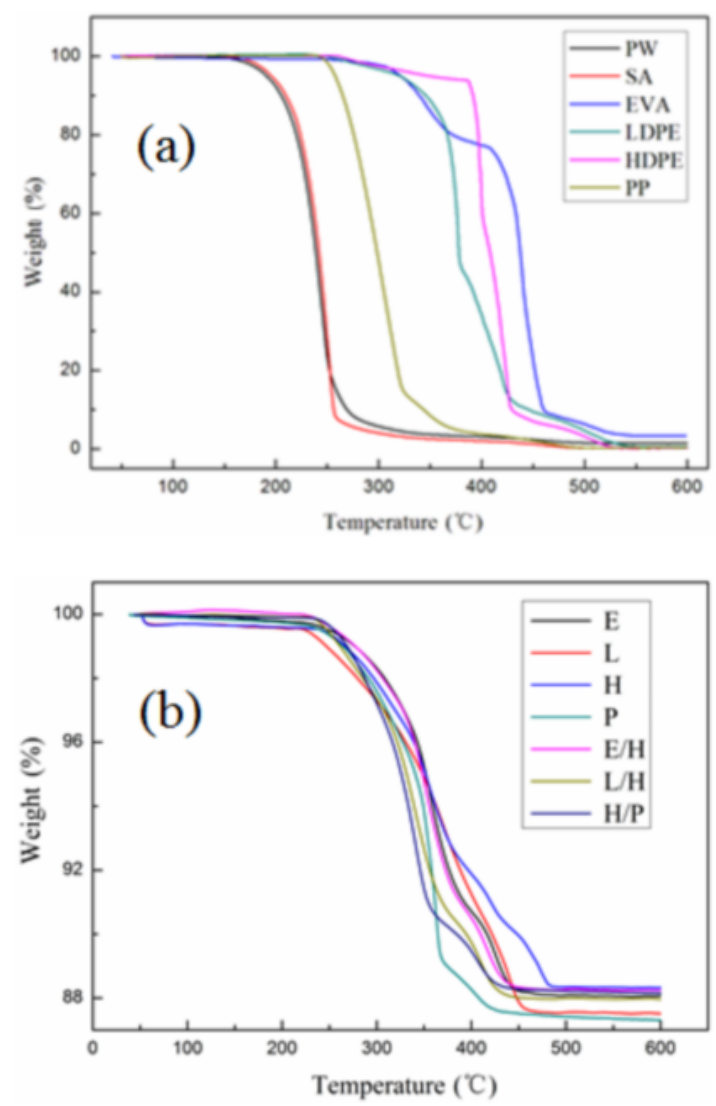

Fig. 2 TGA of (a) binder components and (b) feedstocks with various backbone binders.
Also, the bulk densities were measured by Archimedes method.

To determine flexural strength of the green and sintered parts, 3-point bending test was measured in a universal mechanical tester (AG-IC, Shimadzu, Japan). Flexural test rectangular specimens were fabricated on an injection molding machine (Arburg 270c, Arburg Machinery Co. Ltd., Germany). The test pieces had the dimensions of $30 \mathrm{~mm}$ in length, $3 \mathrm{~mm}$ in thickness, and $4 \mathrm{~mm}$ in width.

\section{Results and discussion}

\section{1 The effect of various backbone binders on injection molding}

During ceramic injection molding, there are usually some defects occurred in the inhomogeneous feedstock such as density gradient and distortion [18]. So the homogeneous degree is an important factor to determine the final properties of parts by CIM. Comparing the standard deviation of pycnometer density is a common route to examine the homogeneous degree of feedstock [18]. Feedstocks with various backbone binders show different densities; however, the deviation of pycnometer density can still reflect the trend of homogeneity of feedstock. As shown in Fig. 3, compared to the feedstocks containing multi-polymers, the ones with mono-polymers exhibit larger standard deviation, which indicates much lower homogeneous degree and is more likely to lead to density gradient and distortion within the injection molded parts [18]. This can be attributed to the fact that multi-polymers exhibit more bonding form to implant on the surface of ceramic particles and more stable potential delivery which is more effective to prevent binder segregation [19]. Figure 4 shows the effect of various polymers on the green (as-molded) and as-leached strength. Hidalgo et al. [20] considered that the intrinsic mechanical properties of thermal polymers utilized in the binder system are a key factor to determine the strength of injection molded parts. In addition, thermal polymers used in this work are EVA, LDPE, HDPE, and PP. Usually, the mechanical properties from high to low are in the order of PP, HDPE, LDPE, and EVA. However, as-molded part containing EVA shows unusual mechanical properties. This can be interpreted as that EVA possesses more branched chains (as shown in Fig. 4(b)) which provide more origins of force on the surface of ceramic particles and these will enhance the 
connection between ceramic particles and binders. Unfortunately, after immersing in kerosene for $20 \mathrm{~h}$, parts containing EVA present lots of defects and poor mechanical properties, as shown in Figs. 4 and 5. So parts containing EVA are not suitable for adopting solvent (kerosene) debinding process, which will be discussed in detail later. For the parts using other backbone binders, no defects are found on their surface; moreover, the as-leached strength is all higher than $5 \mathrm{MPa}$ which is the minimum requirement for proceeding to the next stage [3].

\section{2 The effect of various backbone binders on solvent debinding}

To obtain the influence of different backbone binders on

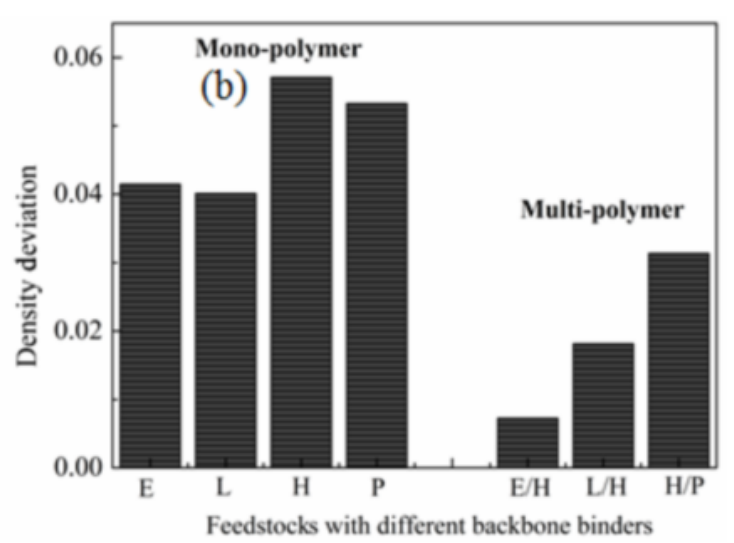

Fig. 3 (a) Pycnometric density of feedstocks with various thermal polymers; (b) deviation of density with different thermal polymers.

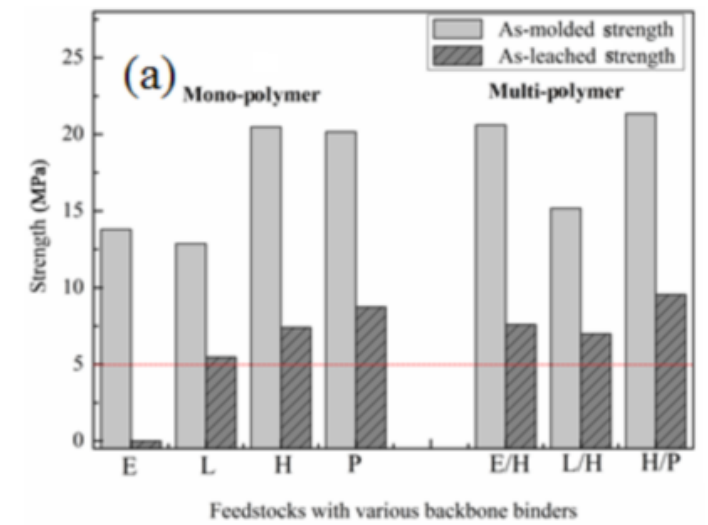

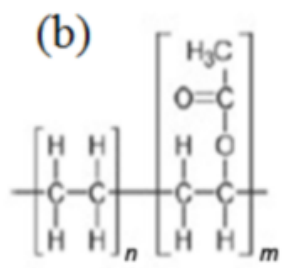

Ethylene-Vinyl acetate (EVA)

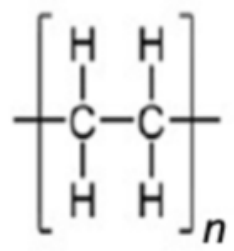

Polyethylene

(PE)<smiles>CC(C)(C)CC(C)(C)C</smiles>

Polypropylene

(PP)

Fig. 4 (a) As-molded strength and as-leached strength of feedstocks with varieties of polymers; (b) the structural formula of backbone binders utilized [19].

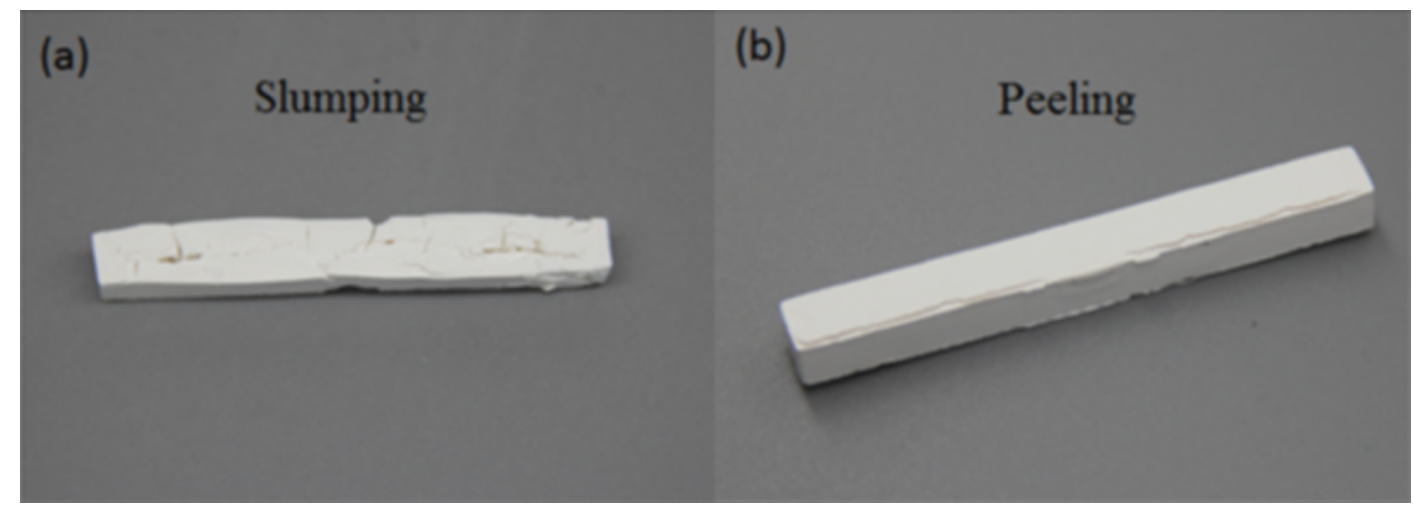

Fig. 5 The defects appeared in the solvent debinding: (a) "slumping" in the part with EVA (E); (b) "peeling" in the part with EVA/HDPE (E/H). 
injection molded parts during solvent debinding, all of parts were firstly immersed in a bath with kerosene at $60{ }^{\circ} \mathrm{C}$. Interestingly, there are lots of defects presented in injection molded parts containing EVA, as shown in Fig. 5. For the part utilizing EVA as the backbone binder, lots of cracks are spreading all over the part, leading to "slumping". With the addition of HDPE to EVA, the cracks in the part are observably reduced; however, defects such as "peeling" are still present. For the defects occurred in the part using EVA during solvent debinding, Li et al. [21] explained that it is caused by the large volume swelling of EVA during solvent debinding, and this has been verified by comparing the volume swelling ratio of $\mathrm{PE}$ and $\mathrm{EVA}$ in $\mathrm{CH}_{2} \mathrm{Cl}_{2}$. However, Zaky et al. [22] achieved the debound part without defects which is containing EVA by immersing in petroleum ether, n-pentane, and diethyl ether. Hence, as the different types of solvent are adopted, the effect on EVA is various. Four kinds of polymers, EVA, LDPE, HDPE, and PP were molded as test bars to investigate their influence on the debinding process. In this experiment, four thermal polymer test bars were all immersed in kerosene at $60{ }^{\circ} \mathrm{C}$, and the change of length, width, and thickness was recorded every $5 \mathrm{~min}$ to estimate their volume swelling ratio. Compared to other thermal polymers showing the behavior of volume swelling in kerosene, the test bar with EVA exhibits softening, gelatinous, and gradually dissolves at last. So we conclude that "slumping" appeared in part utilizing EVA as backbone binder can be interpreted as EVA can form to gel, further, dissolve in kerosene, and finally lose mechanical properties. HDPE [23], a semicrystalline polymer, can reduce some volume swelling and keep the integrity of part after the dissolution of PW and SA. However, for the E/H parts, the molecular weight of EVA is much more than PW or SA, and the stress caused by volume swelling would be stronger than PW and SA, so the cracks or bubbles are easily appeared in the parts, as shown in Fig. 5(b). Also, more paths (see Fig. 6(a) red circle) would be developed and the debinding rate will be increased, as shown in Fig. 7(b). According to Fig. 7(a), LDPE shows the largest volume swelling among three thermal polymers. This means that the diameter of channels (Fig. 6(b) red circle) in the parts using LDPE formed during solvent debinding would be larger than that in the parts using other two thermal polymers. Meanwhile, the debinding rate will be increased and the part must be subjected to stronger stress. The $\mathrm{L} / \mathrm{H}$ sample, taking the capacity of the large volume swelling of LDPE and reducing volume swelling of HDPE, exhibit a fast debinding rate and small and uniform pores (as shown in Fig. 6(c)), which is in favor of densification during the next sintering stage.
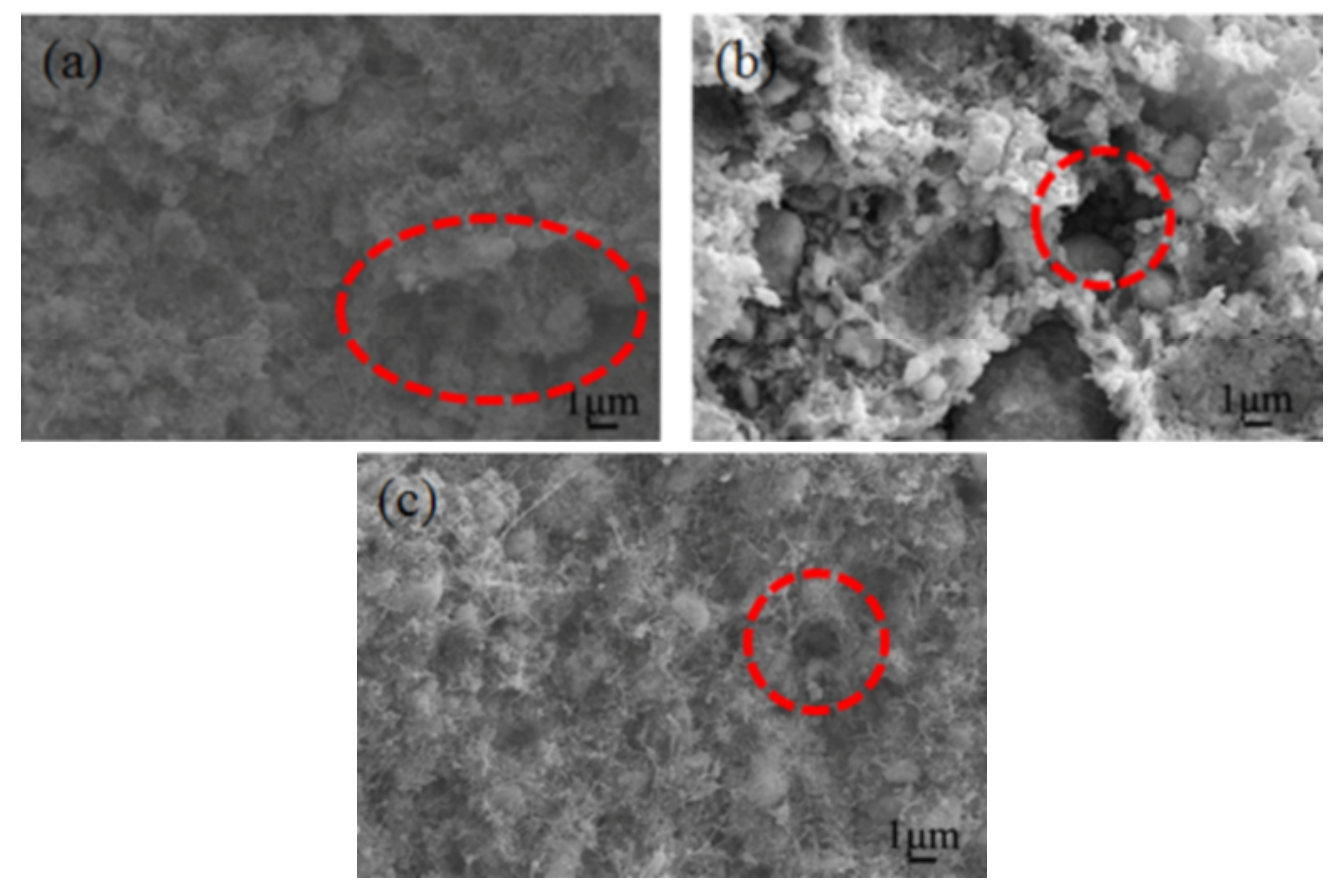

Fig. 6 Scanning electron micrographs of the parts using various thermal polymers after leaching in kerosene at $60{ }^{\circ} \mathrm{C}$ for $20 \mathrm{~h}$ : (a) EVA and HDPE (E/H), (b) LDPE (L), (c) LDPE and HDPE (L/H). 

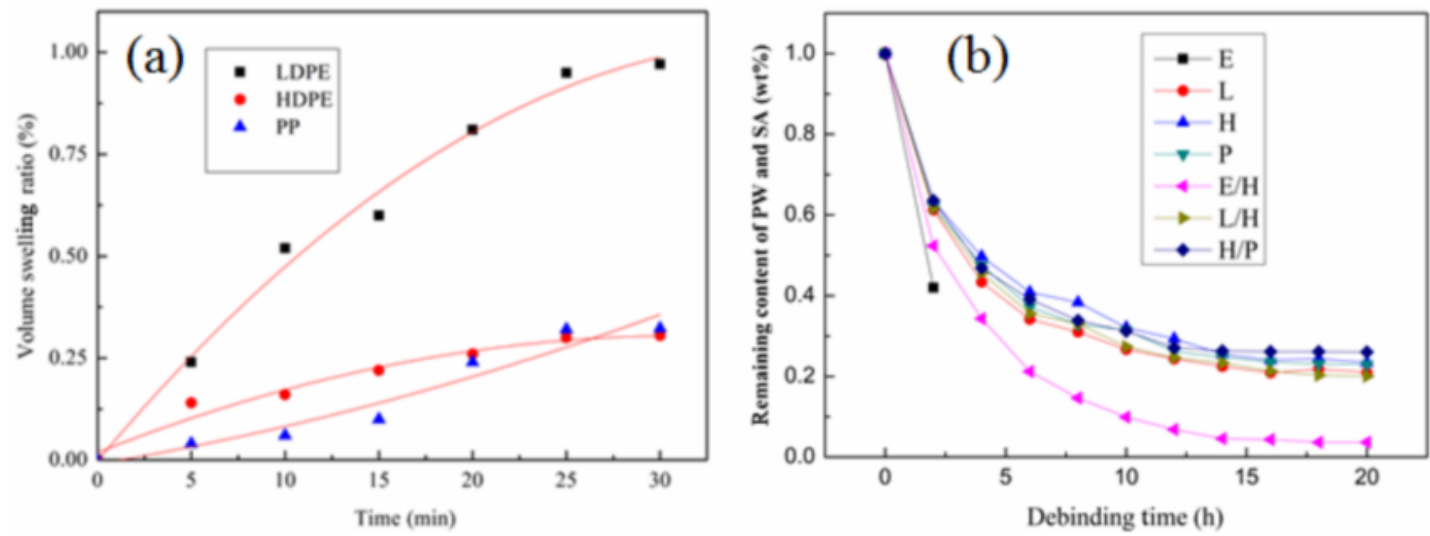

Fig. 7 (a) Volume swelling ratio of LDPE, HDPE, and PP in kerosene at $60{ }^{\circ} \mathrm{C}$; (b) effect of different backbone binders on weight loss of $\mathrm{PW}$ and $\mathrm{SA}$ at $60{ }^{\circ} \mathrm{C}$ for various immersion time.

\section{3 The effect of various backbone binders on sintered properties}

After debinding, sintering was performed on the debound parts to study the effects of backbone binders on microstructure, relative density, and flexural strength $(\sigma)$. All the parts were sintered with a rate of $2.5^{\circ} \mathrm{C} / \mathrm{min}$ to $1500{ }^{\circ} \mathrm{C}$ for $2 \mathrm{~h}$ in a furnace. Also, mechanical properties and density of the samples sintered from the feedstocks with various backbone binders are summarized in Table 2 . It can be easily found that the density is various as different backbone binders are utilized. Particularly, the maximum of relative density $(\sim 98.9 \%)$ is achieved in the $\mathrm{L} / \mathrm{H}$ sample, and the $\mathrm{E} / \mathrm{H}$ sample acquires the minimum value $(\sim 92.9 \%)$. For the $\mathrm{L} / \mathrm{H}$ sample, it can be deduced that with the addition of lower viscosity polymer LDPE to binders, small molecular binder PW will exhibit more activity of migration and thermal polymer (HDPE) will be more dispersive by the migration of the molten PW fluid. Finally, as the uniform and small pores are formed during the solvent debinding process, the next densification process will be proceeding more easily, and finer and more homogeneous grains will be obtained at last, as shown in Fig. 8(e). For the E/H sample, as the pores formed in the debinding process are too large, the distance of particle migration will be too far which will be more difficult in densification, or in other words, it needs more sintering driving force to be densification. And this will result in non-uniform shrinkage of particles which usually leads to voids. For the L sample, as the large volume swelling of LDPE, larger diameter pores formed in the debinding process may be difficult to "heal" during the densification process; therefore, voids are frequently present on the surface and thus result in the deterioration of their mechanical properties. In addition, as the sizes of pores formed in debinding process are various, the growth conditions of grains become different. For the $\mathrm{L}$ and $\mathrm{E} / \mathrm{H}$ samples, the distance between adjacent grains is much larger than the $\mathrm{L} / \mathrm{H}$ sample, so that the number of grains with abnormal growth will be much more than the $\mathrm{L} / \mathrm{H}$ sample. Finally, the $\mathrm{L} / \mathrm{H}$ sample exhibits more homogeneous and finer grains. In view of improving strength, both higher density and smaller grain size play important roles in the overall strength [24]. Thus, the L/H sample with the highest density and finer grain exhibits the highest flexural strength ( $\sim 949 \mathrm{MPa})$; by contrast, the lowest density and the existence of severe pores restrict the mechanical properties of the $\mathrm{E} / \mathrm{H}$ sample.

Table 2 Mechanical properties and relative density of the samples sintered from the feedstocks with various thermal polymers

\begin{tabular}{ccccc}
\hline $\begin{array}{c}\text { Backbone } \\
\text { binder }\end{array}$ & $\begin{array}{c}\text { Flexural } \\
\text { strength (MPa) }\end{array}$ & $\begin{array}{c}\text { Deviation } \\
\text { value (MPa) }\end{array}$ & $\begin{array}{c}\text { Relative } \\
\text { density (\%) }\end{array}$ & $\begin{array}{c}\text { Deviation } \\
\text { value (\%) }\end{array}$ \\
\hline LDPE (L) & 509 & \pm 129 & 96.5 & \pm 0.11 \\
HDPE (H) & 746 & \pm 230 & 97.4 & \pm 0.16 \\
PP (P) & 751 & \pm 180 & 97.5 & \pm 0.14 \\
E/H & 412 & \pm 60 & 92.9 & \pm 0.07 \\
L/H & 949 & \pm 105 & 98.9 & \pm 0.03 \\
H/P & 835 & \pm 119 & 98.6 & \pm 0.05 \\
\hline
\end{tabular}

\section{Conclusions}

Feedstocks with various backbone binders for shaping zirconia powder through ceramic injection molding have been fabricated and tested. Among these thermal polymers, multi-polymers are more competitive than mono-polymers. However, EVA often leads to some defects during solvent debinding because of its dissolvability in kerosene, so the parts with EVA will be 


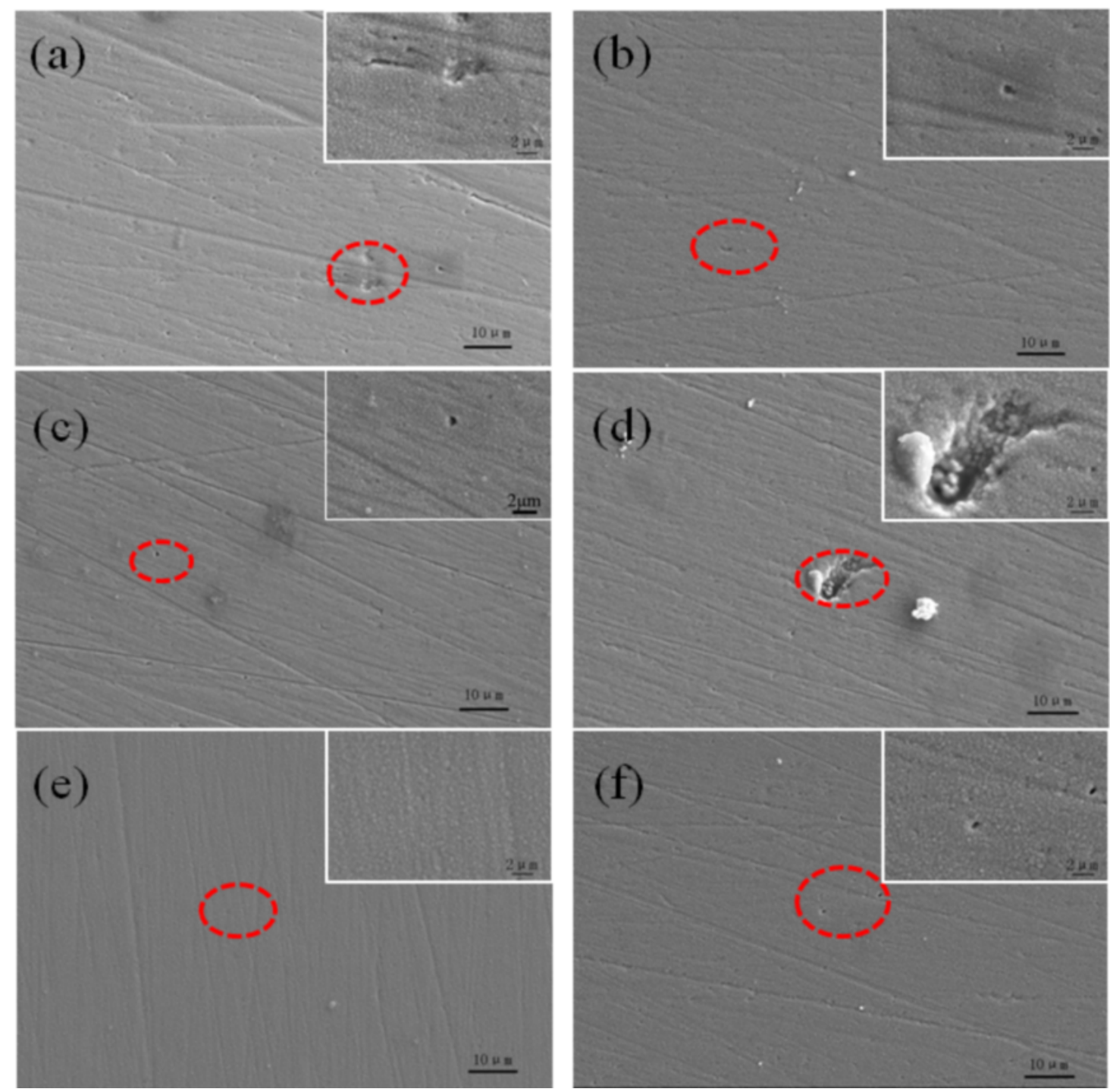

Fig. 8 The as-sintered surfaces of the sintered bodies for the 3Y-TZP with different backbone binders, whose pores originate from debinding: (a) L, (b) H, (c) P, (d) E/H, (e) L/H, (f) H/P.

not suitable for adopting the combination of solvent and thermal debinding process. Finally, multi-polymer (LDPE and HDPE) shows the suitable characteristic to be injected. Also, the highest flexural strength $(\sim 949 \mathrm{MPa})$ and relative density $(\sim 98.9 \%)$ are achieved in the parts using $\mathrm{L} / \mathrm{H}$ after sintering at $1500{ }^{\circ} \mathrm{C}$ for $2 \mathrm{~h}$.

\section{Acknowledgements}

This work was financially supported by National Natural Science Foundation of China (Grant No. 51572035).

\section{References}

[1] Mutsuddy BC, Ford RG. Ceramic Injection Molding.
London: Chapman \& Hall, 1995: 1-22.

[2] German RM. Powder Metallurgy Science, 2nd edn. Princeton, NJ, USA: MPIF, 1994.

[3] German RM. Powder Injection Molding. Princeton, NJ, USA: MPIF, 1990.

[4] Lin ST, German RM. Interaction between binder and powder in injection molding of alumina. J Mater Sci 1994, 29: 5207-5212.

[5] Liu D-M, Tseng WJ. Yield behavior of zirconia-wax suspensions. Mat Sci Eng A 1998, 254: 136-146.

[6] Trunec M, Cihlar J. Thermal removal of multicomponent binder from ceramic injection moldings. $J$ Eur Ceram Soc 2002, 22: 2231-2241.

[7] Zhang T, Evans JRG. Relaxation effects in large injection molded ceramic bodies. J Eur Ceram Soc 1993, 12: 51-59.

[8] Yang S, Zhang R, Qu X. X-ray analysis of powder-binder separation during $\mathrm{SiC}$ injection process in $\mathrm{L}$-shaped mould. J Eur Ceram Soc 2015, 35: 61-67.

[9] Thomas-Vielma P, Cervera A, Levenfeld B, et al. 
Production of alumina parts by powder injection molding with a binder system based on high density polyethylene. $J$ Eur Ceram Soc 2008, 28: 763-771.

[10] Liu ZY, Loh NH, Tor SB, et al. Binder system for micropowder injection molding. Mater Lett 2001, 48: 31-38.

[11] Yang W-W, Yang K-Y, Wang M-C, et al. Solvent debinding mechanism for alumina injection molded compacts with water-soluble binders. Ceram Int 2003, 29: 745-756.

[12] Liu W, Xie Z, Zhang L, et al. Debinding behaviors and mechanism of injection molded $\mathrm{ZrO}_{2}$ ceramics using kerosene as solvents. Key Eng Mater 2012, 512-515: 431-434.

[13] Matula G, Dobrzański LA, Varez A, et al. Development of a feedstock formulation based on PP for MIM of carbides reinforced M2. Journal of Achievements in Materials and Manufacturing Engineering 2008, 27: 195-198.

[14] Islam $\mathrm{SH}, \mathrm{Qu} \mathrm{XH}$, Tufai M. Preparation and characterization of tungsten heavy alloy feedstock for metal injection molding. Adv Mater Res 2007, 26-28: 363-366.

[15] Kim SW, Lee H-W, Song H. Effect of minor binder on capillary structure evolution during wicking. Ceram Int 1999, 25: 671-676.

[16] Setasuwon P, Bunchavimonchet A, Danchaivijit S. The effects of binder components in wax/oil systems for metal injection molding. J Mater Process Tech 2008, 196: 94-100.

[17] Ani SM, Muchtar A, Muhamad N, et al. Binder removal via a two-stage debinding process for ceramic injection molding parts. Ceram Int 2014, 40: 2819-2824.
[18] Supati R, Loh NH, Khor KA, et al. Mixing and characterization of feedstock for powder injection molding. Mater Lett 2000, 46: 109-114.

[19] González-Gutiérrez J, Stringari G, Emri I. Powder injection molding of metal and ceramic parts. In Some Critical Issues for Injection Molding. Wang J, Ed. InTech, 2012: 65-88.

[20] Hidalgo J, Abajo C, Jiménez-Morales A, et al. Effect of a binder system on the low-pressure powder injection moulding of water-soluble zircon feedstocks. J Eur Ceram Soc 2013, 33: 3185-3194.

[21] Li S, Huang B, Li Y, et al. A new type of binder for metal injection molding. J Mater Process Tech 2003, 127: 70-73.

[22] Zaky MT, Soliman FS, Farag AS. Influence of paraffin wax characteristics on the formulation of wax-based binders and their debinding from green molded parts using two comparative techniques. J Mater Process Tech 2009, 209: 5981-5989.

[23] Goodship V. Practical Guide to Injection Moulding. Shawbury, UK: Rapra Technology, 2004.

[24] Lee S-Y. Sintering behavior and mechanical properties of injection-molded zirconia powder. Ceram Int 2004, 30: 579-584.

Open Access The articles published in this journal are distributed under the terms of the Creative Commons Attribution 4.0 International License (http://creativecommons. org/licenses/by/4.0/), which permits unrestricted use, distribution, and reproduction in any medium, provided you give appropriate credit to the original author(s) and the source, provide a link to the Creative Commons license, and indicate if changes were made. 